\title{
SURGICAL OUTCOME OF LID SPARING ORBITAL EXENTERATION WITH PRESERVATION OF THE ORBITAL PERIOSTEUM FOR SOCKET AND LID RECONSTRUCTION
}

\author{
Salil Kumar Mandal1, Tamojit Chatterjee ${ }^{2}$, James Christian Fleming ${ }^{3}$
}

${ }^{1}$ Associate Professor, Department of Orbit and Oculoplasty, Regional Institute of Ophthalmology, Medical College, Calcutta. ${ }^{2}$ Clinical Tutor cum RMO, Department of Orbit and Oculoplasty, Regional Institute of Ophthalmology, Medical College, Calcutta. 3Professor and Chairman, University of Tennessee, Department of Ophthalmology, Ophthalmic Plastic and Reconstructive Surgery, Hamilton Eye Institute, Memphis, United States.

\section{ABSTRACT}

\section{BACKGROUND}

Orbital exenteration is a life-saving desperate procedure to remove the whole eyeball along with muscle, fascia, fat, etc. It is commonly performed in case of intraocular malignancy, which invade extraocular orbital content. It may be primary from eyeball itself or secondary from the other source, e.g. breast, lungs, bone. After lid sparing orbital exenteration, forehead rotational flap was made for lid reconstruction and it achieves acceptable functional cosmetic appearance.

The aim of the study was to evaluate the surgical and cosmetic outcome of lid sparing orbital exenteration with preservation of orbital periosteum and recurrence of the malignancy, effectiveness of socket and lid reconstruction after forehead rotational flap, split thickness and dermis fat graft.

\section{MATERIALS AND METHODS}

This was a descriptive case study of thirty eyes and patients over a period of four years. In this study, mean age of the patient was 67.93. Male-to-female ratio was 2:3. All the patients had biopsy proven ocular malignancy with spreading tendency. Peroperative all quadrant frozen section biopsy, map biopsy and optic nerve stump biopsy were performed in all the cases. Lid sparing orbital exenteration with the preservation of orbital periosteum was performed in all the cases. Simultaneously, forehead rotational flap for lid reconstruction and split thickness skin graft and dermis fat graft was made for lid and socket reconstruction. Patient was followed up for six months to two years.

\section{RESULTS}

Total number of patients was thirty, of which males were 12 and females were 18. Lid sparing orbital exenteration with preservation of orbital periosteum was performed in all the cases. Simultaneously, forehead rotational flap was made for lid reconstruction. All the patients were followed up for six months to two years. No such recurrence of the disease was seen. All the patients had moderate-to-good cosmetic outcome with adequate prosthetic fitting. Peroperative all quadrant frozen sections, map biopsy and optic nerve stump biopsy were performed in all the cases. Most of the cases were categorised as orbital, ocular and adnexal malignancy with squamous cell carcinoma (40\%) and basal cell carcinoma (23\%) being the most common. Mesothelial tumours $6 \%$ and Adenoid cystic carcinoma $1(3 \%)$ were the least in this study. Complications occurred in some of the cases as infection and partial graft rejection. All the thirty patients had satisfactory surgical, cosmetic and functional outcome. Preservation of the orbital periosteum is much effective for split thickness skin graft and dermis fat graft to accept the host orbital bed. Simultaneously, successful lid reconstruction was performed from temporal arterial base, forehead rotational flap for prosthetic fitting and better cosmetic appearance.

\section{CONCLUSION}

Lid sparing orbital exenteration with preservation of orbital periosteum is effective for socket and lid reconstruction. Split thickness skin graft and dermis fat graft were effective for socket reconstruction. Satisfactory cosmetic and functional outcome of the orbit and lid was achieved after successful forehead rotational flap operation. Early diagnosis and treatment avoid the destructive surgery and preserve orbital periosteum. No such recurrence of malignancy was seen in six months to two-year followup period. Overall, patient's psychological and social rehabilitation was much more improved.

\section{KEYWORDS}

Malignancy, Reconstruction, Forehead Flap.

HOW TO CITE THIS ARTICLE: Mandal SK, Chatterjee T, Fleming JC. Surgical outcome of lid sparing orbital exenteration with preservation of the orbital periosteum for socket and lid reconstruction. J. Evolution Med. Dent. Sci. 2017;6(71):5069-5074, D0I: $10.14260 /$ Jemds/2017/1102

Financial or Other, Competing Interest: None.

Submission 29-07-2017, Peer Review 22-08-2017,

Acceptance 28-08-2017, Published 04-09-2017.

Corresponding Author:

Dr. Salil Kumar Mandal,

Associate Professor, Regional Institute

of Ophthalmology, Medical College of Calcutta,

183, R. N. Guha Road, Dumdum,

Calcutta-700074.

E-mail: salil_dum@live.com

DOI: $10.14260 /$ jemds $/ 2017 / 1102$

\section{BACKGROUND}

Orbital exenteration is commonly performed in cases of malignant neoplasm of the orbital content either by primary or secondary from adjacent structure, which is not treated with simple excision or radiotherapy. In this procedure, there is not only removal of the eyeball, there is also removal of surrounding structure, e.g. extraocular muscle, fat and soft tissue. Orbital exenteration was classified as total, subtotal and super exenteration. According to Levin et al, indication of orbital exenteration were as follows- Life-threatening malignancy, life-threatening infection, intractable pain and 
deformity. In this study, all the 28 cases were done for malignancy with life-threatening situation and two cases for intractable infection and inflammation. Lid sparing orbital exenteration with preservation of the orbital periosteum was performed in all the cases. Split thickness skin grafting and dermis fat graft was performed to cover orbital periosteum for prosthetic bed. Forehead rotational flap was performed for lid reconstruction and fitting of prosthesis and achieved an acceptable cosmesis.[1,2,3,4,5]

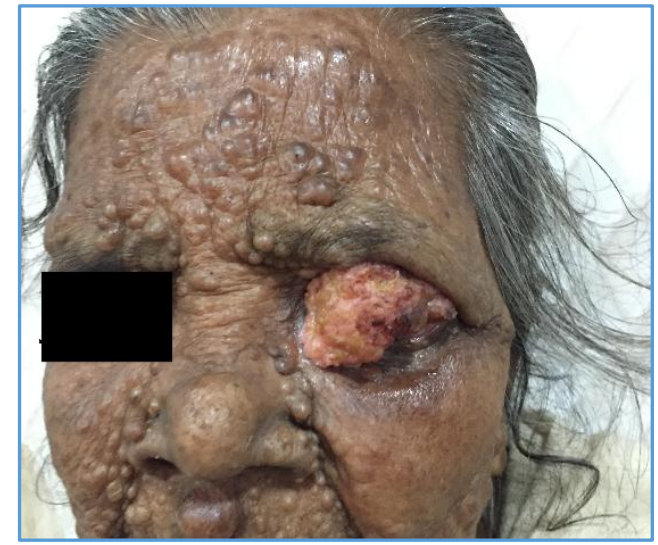

Figure 1. Preoperative Image of Ocular Surface
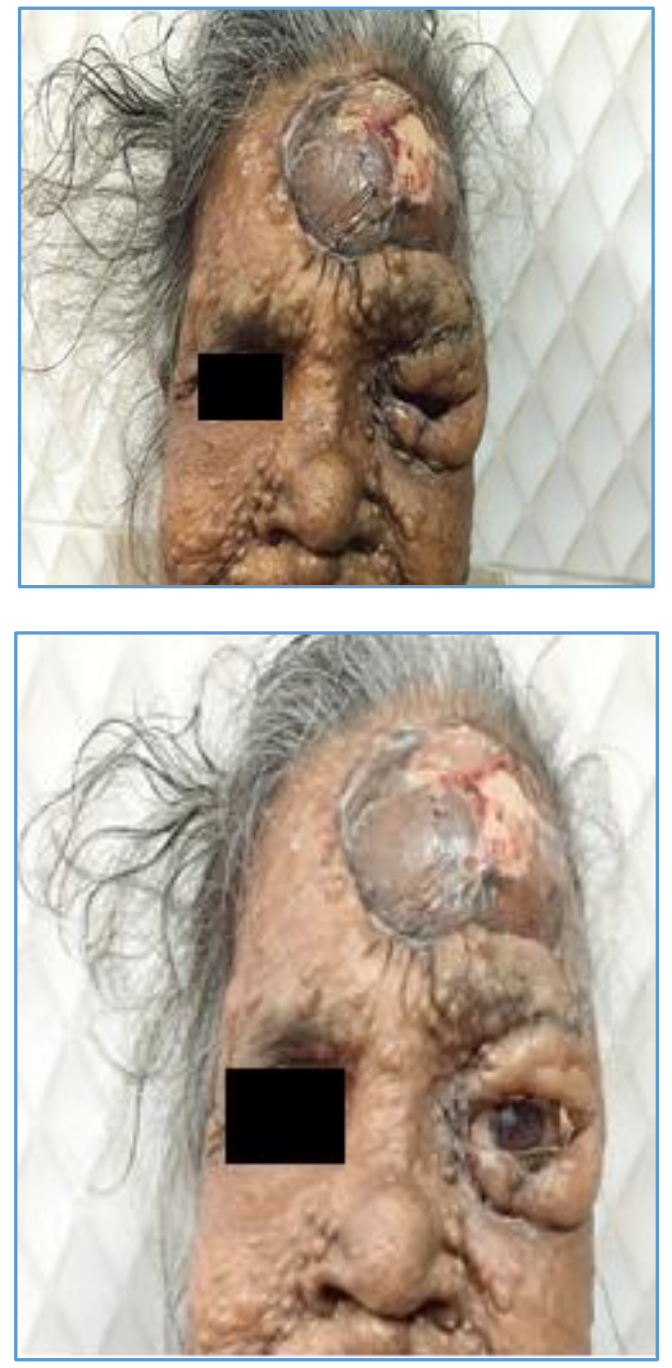

Figure 2. Post-Operative Image of Lid Sparing Orbital Tumour Exenteration with Rotational Flap and Prosthesis

\section{Aims and Objectives}

To evaluate effectiveness of socket and lid reconstruction after lid sparing orbital exenteration with preservation of orbital periosteum for split thickness skin graft and forehead rotational flap with recurrence of malignant tumour; to evaluate the cosmetic outcome after prosthetic fitting and psychosocial status of the patient.

\begin{tabular}{|c|c|}
\hline 1 & $\begin{array}{c}\text { Ocular surface 65.6 } \pm \text { 13.8, male 3, female 9, BCC 4, SCC } \\
\text { 8, LN 0 Lung 0, Fatty Liver n= 10 } \\
\text { Neoplasm (12) }\end{array}$ \\
\hline 2 & $\begin{array}{c}\text { Eyelid neoplasm (8) 62.78 } \pm 11.6, \text { male 4, female 4, BCC } \\
\text { 2, SCC 2, SGC 4, Suspicious LN 2, Fatty Liver n=4 } \\
\text { Spreading to anterior orbit }\end{array}$ \\
\hline 3 & $\begin{array}{c}\text { Intraocular neoplasm n (2) 74.5 } \pm \text { 8.20, male 1, female } \\
\text { 1, FNAC 0, LN 0, Fatty Liver 2 }\end{array}$ \\
\hline 4 & $\begin{array}{c}\text { Lacrimal gland neoplasm (1) 53, male 1, adenoid cystic } \\
\text { CA, LN 0, Lung 0, Fatty Liver 1 }\end{array}$ \\
\hline 5 & $\begin{array}{r}\text { Intractable orbital infection 68.74 } \pm \text { 8.20, male 1, } \\
\text { inflammatory cells LN 2 } \\
\text { Fatty Liver 2 (1) }\end{array}$ \\
\hline 6 & $\begin{array}{c}\text { Ocular surface 65.89 } \pm \text { 13.78, male 2, female 2, SCS 4, } \\
\text { BCC 2, LN 0, Lung 0, Fatty Liver 4 } \\
\text { Eyelid Combined (4) }\end{array}$ \\
\hline 7 & $\begin{array}{c}\text { Optic nerve sheath tumour (2) 56.67 } \pm \text { 7.2, female 2, } \\
\text { FNAC 0, LN 0, Lung 0, Fatty Liver 0 }\end{array}$ \\
\hline $\begin{array}{c}\text { Table 1. Primary Site, Average Age } \pm \text { SD, Sex Distribution } \\
\text { Preop FNAC, Lymph Node, Lung, Liver Bone, any Lesion } \\
\text { Total No. of Patients n= 30 }\end{array}$ \\
\hline
\end{tabular}

\section{MATERIALS AND METHODS}

Medical record was collected from Medical College of Calcutta, Department of Ophthalmology, Plastic Surgery and Radiotherapy. This study was conducted in Regional Institute of Ophthalmology of Medical College of Calcutta from March 2013 to December 2017. This was a descriptive case study of thirty eyes. All investigators adhered to the principles outlined in the declaration of the Institutional Ethics Committee at the Medical College of Calcutta in Kolkata, India. Simple statistical data analysis was done in excel sheet. All the patients had biopsy proven ocular malignancy with spreading tendency. In this study, 12 patients were male and 18 patients were female. Lid sparing orbital exenteration with preservation of orbital periosteum was performed in all the cases. Split thickness skin graft was performed to cover the orbital bone in $73 \%$ of cases and dermis fat graft in $27 \%$ cases. Simultaneously, sockets and lid reconstruction was performed for prosthetic fitting. Patients were followed up for six months to two years. Inclusion criteria in this study was malignancy strictly to orbital content without invading the periosteum. Malignancy invade the lid margin up to $2-3$ $\mathrm{mm}$. No h/o chemotherapy or radiotherapy. Regional lymph node biopsy was negative. Exclusion criteria were malignancy which has spread to adjacent structures invading the periosteum, distant metastasis, regional lymph node biopsy positive cases, $\mathrm{h} / \mathrm{o}$ chemotherapy and radiotherapy in cases of proven malignancy. CT scan and MRI was done in all the cases. CT scan helps to evaluate the extent of the disease and bone involvement and MRI is better for tissue differentiation and posterior invasion of the tumour mass or tumour with perineural spread. 
In all the cases, mass was in anterior part of the globe and partly involved the lid. Some tumours involved the lid and anterior orbit. Retro-orbital part and optic nerve was absolutely free. In this study, age ranges from 45 to 80 mean age with SD of $67.93 \pm 8.16$ and male-to-female ratio was 2:3. Squamous cell carcinoma $12(40 \%)$, basal cell carcinoma 7 (23.3\%), sebaceous gland carcinoma 5 (16.6\%), malignant melanoma $2(6.6 \%)$, orbital meningeal mesothelial tumours 2 (6.6\%), intractable orbital infection $1(3.3 \%)$ and adenoid cystic carcinoma 1 (3.3\%).

\begin{tabular}{|c|c|}
\hline 1 & $\begin{array}{c}\text { Ocular surface neoplasm } 12, \text { BCC } 4, \text { SCC } 8, \\
\text { Cornea conjunctiva }\end{array}$ \\
\hline 2 & $\begin{array}{c}\text { Eyelid neoplasm spreading } 6, \text { SCC } 2, \text { BCC } 1, \text { SGC 3, } \\
\text { Anterior orbit }\end{array}$ \\
\hline
\end{tabular}

\begin{tabular}{|c|c|}
\hline 3 & \begin{tabular}{c} 
Intraocular neoplasm MM 2 \\
\hline 4
\end{tabular} \\
\hline 5 & $\begin{array}{c}\text { Lacrymal gland neoplasm 1 Adenoid cystic } \\
\text { carcinoma }\end{array}$ \\
\hline 6 & $\begin{array}{c}\text { Intractable orbital infection 1 Antibiotic resistant } \\
\text { infection, 1 } \\
\text { Mucormycosis }\end{array}$ \\
\hline 7 & Ocular surface eyelid combined 4, SCS 2, BCC 2 \\
\hline \multicolumn{2}{|c|}{ Table 2. Tissue Origin, No. of Cases (n), Histopathological } \\
Diagnosis
\end{tabular}

BCC- Basal cell carcinoma, SCC- Squamous cell carcinoma, SGC- Sebaceous gland carcinoma, MM- Malignant melanoma, MST- Meningeal mesothelioma.

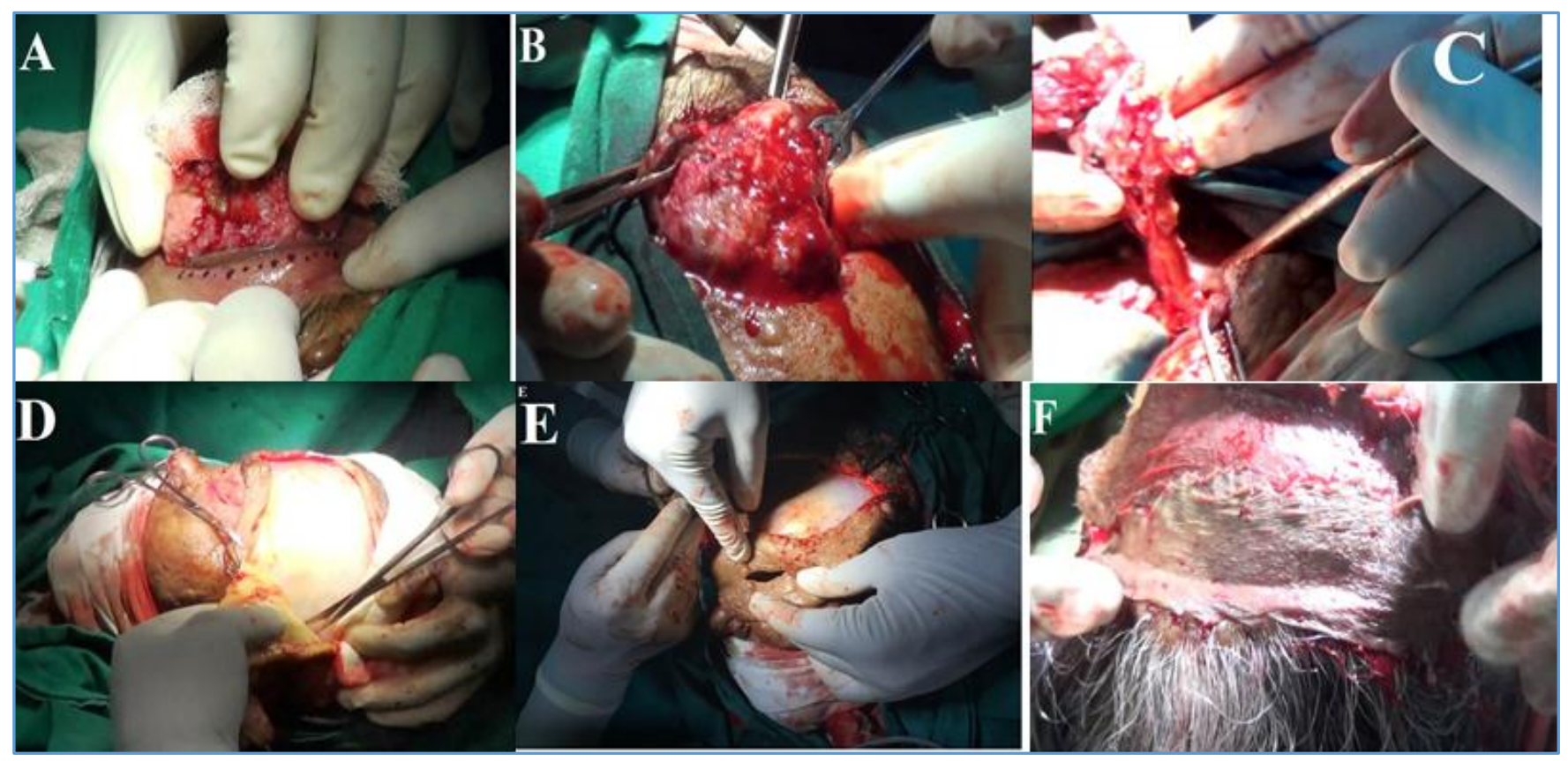

Figure 3A. Incision Marked 8 - 12 mm away from Healthy Lid Margin; 3B. Orbital Septum Incised at Orbital Margin Entrance in Extraconal Space; 3C. Long Optic Nerve Harvest from the Lateral Approach; 3D. Forehead Rotational Flap Made; $3 E$. Palpebral Aperture made over Rotational Flap; 3F. Split Thickness Graft cover the Periosteum over Forehead

\section{Surgical Procedure}

This was a combined effort of both oculoplastic and plastic surgeons and radiation oncologist. Incision line was marked first. Surgical incision was made $4-12 \mathrm{~mm}$ with mean and SD $9.45 \pm 3.45 \mathrm{~mm}$ away from lid margin directly to reach the orbital septum. Orbital septum was exposed, but not to be disturbed. Over the periosteum all the soft tissues including optic nerve with eyeball was removed. In lateral approach, 12 - $16 \mathrm{~mm}$ with mean and SD $13.5 \pm 1.22 \mathrm{~mm}$ length of optic nerve was harvested in all the cases. Thorough map biopsy was taken from all quadrants of the orbit over the periosteum of the orbit and sent for frozen section HP examination. Simultaneously, also optic nerve stump biopsy was performed in frozen section. As soon as all tissues HP report results were negative, we further proceeded for a split thickness skin graft and dermis fat graft mount over periosteum to cover the orbital bone and simultaneously forehead rotational flap mount over the exenterated eye. New palpebral aperture was made over the rotational flap; superior and inferior cut margin was sutured with cut margin of the sparing lid. Followup ranges from six months to two years.

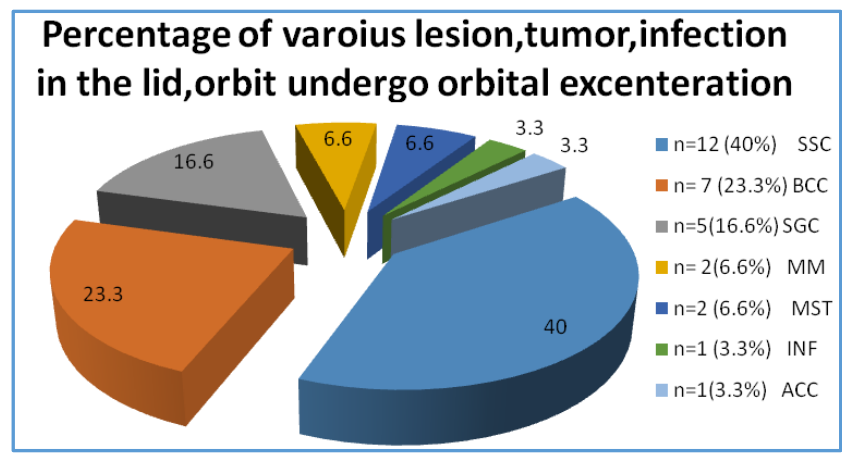

\section{RESULTS}

Total no. of patients was 30 , of which males were 12 and females were 18. Lid sparing orbital exenteration with sparing of the orbital periosteum was performed in all the cases. Simultaneously, forehead rotational flap was made for 
lid reconstruction 22 (73\%), split thickness skin graft was performed in $22(73 \%)$ and dermis fat graft was made in 8 $(27 \%)$ cases. In this study, $40 \%$ patients were followed up for 6 months to 1 year and $60 \%$ were followed up for 1 to 2 years. No such recurrence of the disease. All the patients had moderate-to-good cosmetic outcome with adequate prosthetic fittings. Most of the cases were categorised as orbital, ocular and adnexal malignancy with squamous cell carcinoma 12 (40\%) and basal cell carcinoma 7 (23.3\%), and sebaceous gland carcinoma $5(16.6 \%)$ being the most common. Mesothelial tumours 2 (6.6\%), orbital infection 1 (3.3\%) and adenoid cystic carcinoma $1(3.3 \%)$ were the least in this study. Complications occurred in this study are socket infection 2 (6\%), graft infection $4(13 \%)$, tissue necrosis and escher formation 2 (6\%), non-healing ulcer 1 (3\%) and exposure of implant $1(3 \%)$ number of cases. So all of these complications were treated conservatively with systemic antibiotics and anti-inflammatory drugs and local dressings. In this study, all of the patients had adequate space for prosthesis and good cosmesis throughout the post-operative period except one who had exposure of implant. Healthy lid margin was removed in $4-6 \mathrm{~mm}$ mean, $5.45 \mathrm{~mm}$ in ocular surface tumour group, 8 - $12 \mathrm{~mm}$ with mean, $10.16 \mathrm{~mm}$ with eyelid tumour group and $10-14 \mathrm{~mm}$ with mean and $12.4 \mathrm{~mm}$ in combined lid orbit lesion group. But HP report of all of the patients had margin free tumour mass. Regarding optic nerve, it was harvested in $12-16 \mathrm{~mm}$ with mean of $13.45 \mathrm{~mm}$ in this study and in all of the cases it was tumour free margin. In maximum 2 years of followup period, none died and there was no recurrence of the malignancy in this study.

\begin{tabular}{|c|c|c|c|c|c|c|}
\hline Diagnosis of Lesion & $\begin{array}{c}\text { Lid Sparing } \\
\text { Exenteration with } \\
\text { Healthy Margin } \\
\text { Removal }\end{array}$ & $\begin{array}{l}\text { Length of } \\
\text { Optic } \\
\text { Nerve } \\
\text { Harvest }\end{array}$ & $\begin{array}{c}\text { Type of } \\
\text { Reconstruction } \\
\text { F.H.R Flap, STS } \\
\text { Graft, DF Graft }\end{array}$ & Chemo/Radio & Follow-Up & Prosthesis \\
\hline $\begin{array}{l}\text { Ocular surface } \\
\text { neoplasm }=12\end{array}$ & $4-6 \mathrm{~mm}$ & $10-12 \mathrm{~mm}$ & $\begin{array}{l}\text { F.H.R flap, STS } \\
\text { Graft }=12\end{array}$ & $\begin{array}{c}\text { F.H.R flap, STS } \\
\text { Graft }=12\end{array}$ & $\begin{array}{l}6 \mathrm{~m}-1 \mathrm{yr}=7 \\
1 \mathrm{yr}-2 \mathrm{yrs}=5 \\
\end{array}$ & $\begin{array}{c}1 \text { yr }-2 \text { yrs }=5 \\
\text { PMMA = } 3\end{array}$ \\
\hline Eyelid neoplasm $=6$ & 8-12 mm & $13-16 \mathrm{~mm}$ & $\begin{array}{l}\text { F.H.R flap, } \\
\text { STS Graft= } 6\end{array}$ & Chemo +6 & $\begin{array}{c}6 m-1 \mathrm{yr}=2 \\
\text { HDAPT }=4\end{array}$ & $\begin{array}{c}1 \text { yr }-2 \text { yrs }=4 \\
\text { PMMA }=2\end{array}$ \\
\hline $\begin{array}{c}\text { Intraocular } \\
\text { neoplasm } n=2\end{array}$ & Lid spared & $12-14 \mathrm{~mm}$ & DF Graft $=2$ & Chemo +2 & $1 \mathrm{yr}-2 \mathrm{yrs}=-2$ & $\mathrm{PMMA}=3$ \\
\hline Orbital infection $n=1$ & Lid spared & $12-14 \mathrm{~mm}$ & DF Graft= 1 & $1 \mathrm{yr}-2 \mathrm{yrs}=1$ & & HDAPT $=1$ \\
\hline $\begin{array}{c}\text { Lacrymal } \\
\text { gland neoplasm= } 1\end{array}$ & $10-14 \mathrm{~mm}$ & $10-14 \mathrm{~mm}$ & $\begin{array}{l}\text { F.H.R flap, STS } \\
\text { Graft }=1\end{array}$ & Chemo +1 & $6 m-1 y r=2$ & $\mathrm{HDAPT}=1$ \\
\hline $\begin{array}{c}\text { Orbital mesothelioma= } \\
2\end{array}$ & Lid spared & $12-14 \mathrm{~mm}$ & DF Graft $=2$ & Radio +2 & $1 \mathrm{yr}-2 \mathrm{yrs}=2$ & HDAPT $=2$ \\
\hline $\begin{array}{c}\text { Ocular surface } \\
\text { eyelid combined }=4\end{array}$ & 8-10 mm & $10-14 \mathrm{~mm}$ & $\begin{array}{l}\text { F.H.R flap, STS } \\
\text { Graft }=4\end{array}$ & Chemo + 4 & $\begin{array}{c}6 \mathrm{~m}-1 \mathrm{yr}=3 \\
1 \mathrm{yr}-2 \mathrm{yrs}=1\end{array}$ & $\mathrm{HDAPT}=4$ \\
\hline
\end{tabular}

Polymethylmethacrylate $=$ PMMA, Forehead rotational flap= FHR flap, Split thickness skin graft= STS graft, Dermis fat graft= DF graft, Hydroxyapatite $=$ HDAPT .

\section{DISCUSSION}

Orbital exenteration is a highly disfiguring surgery. It is the first line of surgical procedure when the disease is progressive. It is a life-saving, desperate procedure. Initially, the decision to be taken for orbital exenteration is difficult, but when the tumour progressively invades the orbital fat, muscle, orbital apex, conjunctiva and sclera it must be performed. In this procedure, there is complete removal of tumour mass with local invasive tumour, e.g. squamous cell carcinoma, basal cell carcinoma, sebaceous gland carcinoma, mesothelial tumours, uncontrolled orbital infection and adenoid cystic carcinoma. In this study the mean age of the patient is 67.93, which is similar to Arie Y. Nemet et al works over 38 cases where the mean age was 67.7 in Sydney Eye Hospital in 2007. In this study male-to-female ratio is $2: 3$, male 26 and female 12 in Arie Y. Nemet et al study and 33 male and 35 female in I Rahman's, AE Cook's and B Leatherbarrow's study in 2005, Manchester Royal Eye Hospital, UK. Success of the surgery depends upon tumour free margin before distant metastasis. In orbital exenteration we achieved $100 \%$ tumour free margin, which was comparable with Arie Y. Nemet et al study that achieved (63\%), Ben Simon et al (68\%) and Goldberg et al (62\%). This will help in long-term followup. In this study, there was no recurrence and death within six to two years followup period. It was due to the inclusion and exclusion criteria. In this study $60 \%$ tumours originated from the ocular surface (conjunctiva, cornea), 20\% tumours arose from eyelid and $10 \%$ of the tumours from orbital space tissue, e.g. mesothelioma and adenocystic carcinoma and 10\% from intraocular origin as malignant melanoma.[6,7,8,9,10,11,12] Nowa-days, the new advent of adjuvant chemotherapy and radiotherapy improve the surgical outcome of the study. Several authors suggest that surgical plan is individualised that depend upon following factors- e.g. tumour location, tumour invading the surrounding tissues, availability of surgical space, biological behaviour of the tumour, lid reconstruction and prosthetic fitting. Lid sparing orbital exenteration results in faster healing, less frequent dressing, easy to reconstruct the lid defect and better aesthetic appearance. It requires early diagnosis and motivate the patient for surgical treatment. Preservation of orbital tissue helps in better lid and socket reconstruction.[13,14,15,16] After exenteration, volume restoration of the posterior orbit can be achieved with the dermis fat graft $(23 \%)$ in this study. Prosthesis is better fit in orbit, but when there is split thickness graft to cover the orbital bone specially designed prosthesis can fit. Disadvantage of the dermis fat graft is SCC slowly grows beneath the graft without any external sign. Tumour recurrence should be diagnosed early when socket reconstruction is performed with split thickness skin 
graft. $[8,9,10]$ Most common indication for exenteration is secondary spread from lid, conjunctiva and orbit to distant part of the body. In this study tumour originated $40 \%$ from the ocular surface (conjunctiva, cornea), 33\% from the eyelid, $13 \%$ from the orbital space tissue e.g. infection and inflammation, mesothelioma, adenocystic carcinoma and $10 \%$ from intraocular tumour e.g. malignant melanoma. Squamous cell carcinoma is the most prevalent in our series. Squamous cell carcinoma (40\%), basal cell carcinoma (23.3\%), sebaceous gland carcinoma (16.6\%), malignant melanoma $(6.6 \%)$, orbital meningeal mesothelial tumour (6.6\%), intractable orbital infection (3.3\%) and adenoid cystic carcinoma (3.3\%).[4,7,8,9,10] This is slightly different than the series described by Rathbun and Associates.[1,2] In contrast they found $30 \%$ of the cases $(14 / 48)$ to be basal cell carcinoma and only $12.5 \%(6 / 48)$ to be squamous cell carcinoma. Squamous cell carcinoma is the more aggressive tumour than the basal cell carcinoma. It requires more extensive surgery, because it may involve perineural involvement. Surgical excision followed by radiotherapy is the mainstay of treatment. BCC is the common eyelid tumour (80\%). Here, the malignant cell arises from the basal or germinal cell of the epidermis. Here, the lesion involved lower eyelid (70\%), medial canthal area, upper lid and lateral canthus. It was locally malignant distant metastasis and it was rare. In this study, it involved conjunctiva and sclera. Orbital exenteration with post-operative radiotherapy expand the lifespan of the patient.[7,8] Optic nerve or meningeal mesothelioma arises from optic nerve sheath. Treatment is controversial. Orbital involvement by intracranial meningioma is rare and arises from the sphenoid bone. Radiotherapy sometimes is helpful.[11,12]

There are various options to reconstruct the orbit after exenteration. Reconstruction procedure may be temporalis muscle transfer, midline forehead flap transfer, dermis fat graft, split thickness skin graft, spontaneous granulation, globe sparing exenteration or eyelid sparing exenteration. Several authors thought about disfiguring effect of the surgery, that is why lid sparing orbital exenteration with preservation of the orbital periosteum was chosen for this study. Over the periosteum, split thickness graft is easy to accept due to its higher vascularity than bare bone. Here in each case, all quadrants map biopsy or scraping of the periosteum with dry gaze was performed. Whatever the materials are collected is sent for frozen section biopsy. As soon as the HP report was negative, the split thickness graft was applied over the orbital bone. In this study, we were mainly stressed over tumour spread into posterior segment or retro-orbital area. CT and MRI often does not clearly diagnose the posterior segment extension of the tumour. CT and MRI helps in the diagnosis of post-operative follow-up and recurrence of the diseases. All quadrants frozen section biopsy is helpful for the decision of next step of operation. Periosteum is the strongest barrier to prevent spread of the tumour. It may cause rapid healing and good cosmetic outcome. Shields and Associates report that eyelid sparing technique can be used in most of the cases of malignant tumours and in more than half of the cases originating in the eyelids. In this study, all the cases were performed with lid sparing orbital exenteration with preservation of orbital periosteum for split thickness skin graft.[17-27]

In this study, always wide excision of the tumour tissue was done as much as possible after removal, routine map biopsy was taken from various parts of the orbit. One must take into consideration the biological behaviour of the tumour. In cases of highly malignant infiltrative tumours such as adenoid cystic carcinoma of the lacrimal gland or conjunctival malignant melanoma which are potentially surgically curable, we prefer a wider surgical margin and additional separate intraorbital map biopsies after removing the tumour en-bloc. Most important part of the patient rehabilitation is the lid reconstruction over exenterated eye. In bare bone, split thickness skin graft is not accepted properly. That is why we prefer periosteum to be preserved in all the cases for head rotational flap mount over the partially excised lid margin for lid reconstruction. This would help in retaining prosthesis with proper support for a longer period. Subtotal exenteration with preservation of orbital tissue volume, eyelids or conjunctiva may facilitate the use of orbital and ocular prosthesis and improve aesthetic and functional outcome. When dural resection along with orbital exenteration is performed lid reconstruction must be done as primary procedure, otherwise there was a risk of meningeal infection. Regarding the complications in this series, socket infection $2(6 \%)$ and partial graft infection and rejection 4 $(13 \%)$ are the most common; tissue necrosis $2(6 \%)$ and nonhealing ulcer 1 (3\%), fistulae formation 1 (3\%) and displacement of the prosthesis $1(3 \%)$. This is treated with simple tract excision and conservative management by systemic antibiotic.[29,30,31] Interestingly, Yassur and Associates report the efficacy of becaplermin gel (recombinant human platelet derived growth factor) for the treatment of chronic orbital ulcer after exenteration. Orbital exenteration is successful in the surgical treatment of squamous cell carcinoma and basal cell carcinoma. Success rate of the surgery depend upon the tumour free margin before metastasis to the distant organ. If the tumour margin is very close, chemotherapy and radiotherapy increases the lifespan of the patient. Aesthetic reconstruction of the exenterated orbit is complicated, but may be associated with good cosmetic results. It is more likely to be successful in cases of subtotal exenteration. After orbital reconstruction, various implants were used as the demand of the patient. It may be hydroxyapatite, polymethylmethacrylate or boneimplanted dentures. In this study, hydroxyapatite implant 22 (73\%) and polymethylmethacrylate PMMA 8 (27\%) were used in all the patients. The best functional and cosmetic outcome were by the ability to wear a prosthetic device, the absence of a patch and the lack of postoperative complications such as sino-orbital fistula.[32,33]

\section{CONCLUSION}

Lid sparing orbital exenteration with preservation of the orbital periosteum for split thickness skin graft followed by forehead rotational flap for socket and lid reconstruction is effective for prosthetic fit. Early diagnosis and treatment avoid the destructive surgery. It is functionally, anatomically and cosmetically much effective in long-term follow-up period. Patient's psychological and social status was much more satisfactory. 


\section{ACKNOWLEDGEMENT}

"The Research was supported by an unrestricted grant from Research to Prevent Blindness." All doctors of Regional Institute of Ophthalmology, Department of Plastic Surgery and Department of Radiotherapy, Medical College of Calcutta and Medical Record Section, Medical College of Calcutta; Department of Ophthalmology, Ophthalmic Plastic and Reconstructive Surgery, Hamilton Eye Institute, Memphis, United States.

Video link

Operative procedure demonstrated in one of the patient in this study

https://youtu.be/dqL3ceWjREU

\section{REFERENCES}

[1] Rathbun JE, Beard C, Quickert MH. Evaluation of 48 cases of orbital exenteration. Am J Ophthalmol 1971;72(1):191-9.

[2] Pushker N, Kashyap S, Balasubramanya R, et al. Pattern of orbital exenteration in a tertiary eye care centre in India. Clin Experiment Ophthalmology 2004;32(1):51-4.

[3] Mauriello JA, Han KH, Wolfe R. Use of autogenously split-thickness dermal graft for reconstruction of the lining of the exenterated orbit. Am J Ophthalmol 1985;100(3):465-7.

[4] Levin PS, Dutton JJ. A 20-year of orbital exenteration. Am J Ophthalmol 1991;112(5):496-501.

[5] Reese AB. Exenteration of the orbit; with transplantation of the temporalis muscle. Am J Ophthalmol 1958;45(3):386-90.

[6] Reese $A B$, Jones IS. Exenteration of the orbit and repair by transplantation of the temporalis muscle. Am J Ophthalmol 1961;51:217-27.

[7] Aurora AL, Blodi FC. Reappraisal of basal cell carcinomas of the eyelids. Am J Ophthalmol 1970;70(3):329-36.

[8] Beard C. Observations on the treatment of basal cell carcinoma of the eyelids. The Wendell L. Huges lecture. Trans AM Acad Ophthalmol 1975;79(5):66470.

[9] Reifler DM, Hornblass A. Squamous cell carcinoma of the eyelid. Surv Ophthalmol 1986;30(6):349-65.

[10] Uusitalo M, Ibarra M, Fulton L, et al. Reconstruction with rectus abdominis myocutaneous free flap after orbital exenteration in children. Arch Ophthalmol 2001;119(11):1705-9.

[11] Mark LE, Kennerdell JS, Maroon JC, et al. Microsurgical removal of a primary intraorbital meningioma. Am J Ophthalmol 1978;86(5):704-9.

[12] Kennerdell JS, Maroon JC, Malton M, et al. The management of optic nerve sheath meningioma. Am J Ophthalmol 1988;106(4):450-7.

[13] Lim N, Mulhern MG, Joshi N, et al. The use of autologous autoclaved bone in orbital reconstruction after exenteration for invasive cutaneous carcinoma. Orbit 2002;21(3):181-7.

[14] Nerad JA, Carter KD, LaVelle WE, et al. The osseointegration technique for the rehabilitation of the exenterated orbit. Arch Ophthalmol 1991;109(7):1032-8.

[15] Sevel D. Exenteration of the orbit using a frontal periosteal flap. Head Neck Surg 1981;4(2):154-60.
[16] Goldberg RA, Kim JW, Shorr N. Orbital exenteration: results of an individualized approach. Ophthal Plast Reconstr Surg 2003;19(3):229-36.

[17] Malhotra R, Chen C, Huilgol SC, et al. Mapped serial excision for periocular lentigo maligna and lentigo maligna melanoma. Ophthalmology 2004;110:2011-8.

[18] McKelvie PA, Daniell M, McNab A, et al. Squamous cell carcinoma of the conjunctiva: a series of 26 cases. Br J Ophthalmol 2002;86(2):168-73.

[19] Cook BE, Bartley GB. Treatment options and future prospects for the management of eyelid malignancies: an evidence-based update. Ophthalmology 2004;108(11):2088-98.

[20] Nemet AY, Martin P, Benger R, et al. Orbital exenteration: a 15-year study of 38 cases. Ophthalmic Plastic and Reconstructive Surgery 2007;23(6):46872.

[21] Rahman I, Cook AE, Leatherbarrow B. Orbital exenteration: a 13 year Manchester experience. $\mathrm{Br} \mathrm{J}$ Ophthalmol 2005;89(10):1335-40.

[22] Simon BGJ, Schwarcz RM, Douglas R, et al. Orbital exenteration: one size does not fit all. Am J Ophthalmol 2003;139(1):11-7.

[23] Shields JA, Shields CL, Demirci H, et al. Experience with eyelid-sparing orbital exenteration: the 2000 tullos 0. Coston lecture. Ophthal Plast Reconstr Surg 2001;17(5):355-61.

[24] Frezotti R, Nuti A. Repair after orbital exenteration. Personal technique. Acta Neurochir 1982;60(12):119-24.

[25] Shore JW, Burks R, Leone CR, et al. Dermis-Fat graft for orbital reconstruction after subtotal exenteration. American journal of ophthalmology 1986;102(2):22836.

[26] Lee GA, Hirst LW. Ocular surface squamous neoplasia. Surv Ophthalmol 1995;39(6):429-50.

[27] Lee GA, Hirst LW. Retrospective study of ocular surface squamous neoplasia. Aust NZ J Ophthalmol 1997;25(4):269-76.

[28] Menon NG, Girotto JA, Goldberg NH, et al. Orbital reconstruction after exenteration: use of a transorbital temporal muscle flap. Ann Plast Surg 2003;50(1):38-42.

[29] Shields JA, Demirci H, Marr BP, et al. Conjunctival epithelial involvement by eyelid sebaceous carcinoma. The 2003 J. Howard Stokes lecture. Ophthal Plast Reconstr Surg 2005;21(2):92-6.

[30] Chao AN, Shields CL, Krema H, et al. Outcome of patients with periocular sebaceous gland carcinoma with and without conjunctival intraepithelial invasion. Ophthalmology 2001;108(10):1877-83.

[31] Bartley GB, Garrity JA, Waller RR, et al. Orbital exenteration at the mayo clinic, 1967-1986. Ophthalmology 1989;96(4):468-73.

[32] Malhotra R, Huilgol SC, Huynh NT, et al. The Australian mohs database; part I: periocular basal cell carcinoma experience over 7 years. Ophthalmology 2004;111(4):624-30.

[33] Yassur I, Hirschbein MJ, Karesh JW. Clinicopathologic reports, case reports, and small case series: 0.01\% becaplermin gel for the treatment of a chronic orbital ulcer after exenteration. Arch ophthalmol 2001;119(12):1858-9. 